\title{
Cutaneous siderosis after extravasation of intravenous iron infusion
}

\section{Mrinal Gupta}

Department of Dermatology, Treatwell Skin Centre, Jammu and Kashmir, India

Corresponding author: Dr. Mrinal Gupta, E-mail: drmrinalgupta@yahoo.com

Sir,

A 40-year-old female presented to us with a 2-month history of an asymptomatic, hyperpigmented patch over the dorsal aspect of left forearm and wrist. There was no history of any similar lesion at any other body site or in the family members. There was no history of application of any topical medication at the site, but, the patient gave history of extravasation of iron infusion at the same site three weeks prior to onset of the lesion, which was administered to her for severe anemia. At the time of extravasation, there was diffuse swelling and erythema at the site for which she was given some analgesics and it subsided within two days. The patient noticed the lesions after three weeks which remained asymptomatic and non-progressive. On examination, a diffuse grayishbrown macule with well defined margins was present over the dorsal aspect of the left forearm and wrist (Fig. la). Laboratory investigations including the iron studies were normal. Histopathology of the macule revealed clustered brown granules consistent with iron pigmentation, seen mostly around the veins in the dermis, which on Prussian blue staining stained blue (Figs. $\mathrm{lb}$ and $\mathrm{lc}$ ). On the basis of history, clinical and histopathological examination, a diagnosis of cutaneous siderosis was made and the patient was advised laser treatment for the same, which she refused owing to the long duration of treatment.

The accumulation of various metal salts in the body may result in pigmentation of the skin, like argyrosis develops after treatment with silver and chrysiasis develops after treatment with gold salts. Siderosis is a disease characterized by the accumulation of iron in various tissues, and can be seen as a side-effect in the injection area after parenteral iron treatment [1]. Cutaneous siderosis after intramuscular iron injections is a well documented condition, but siderosis secondary to extravasation of intravenous iron infusion has been rarely reported [1-4]. It usually manifests as varying shades of grey-brown with no distinct contours at the site of injection. Histological findings in drug-induced siderosis are highly variable; however, dermal pigment particles are often concentrated in the macrophages. Numerous iron loaded macrophages can be seen with perivascular and periadnexal settlements in the entire dermis, and iron deposition can reach the subcutaneous

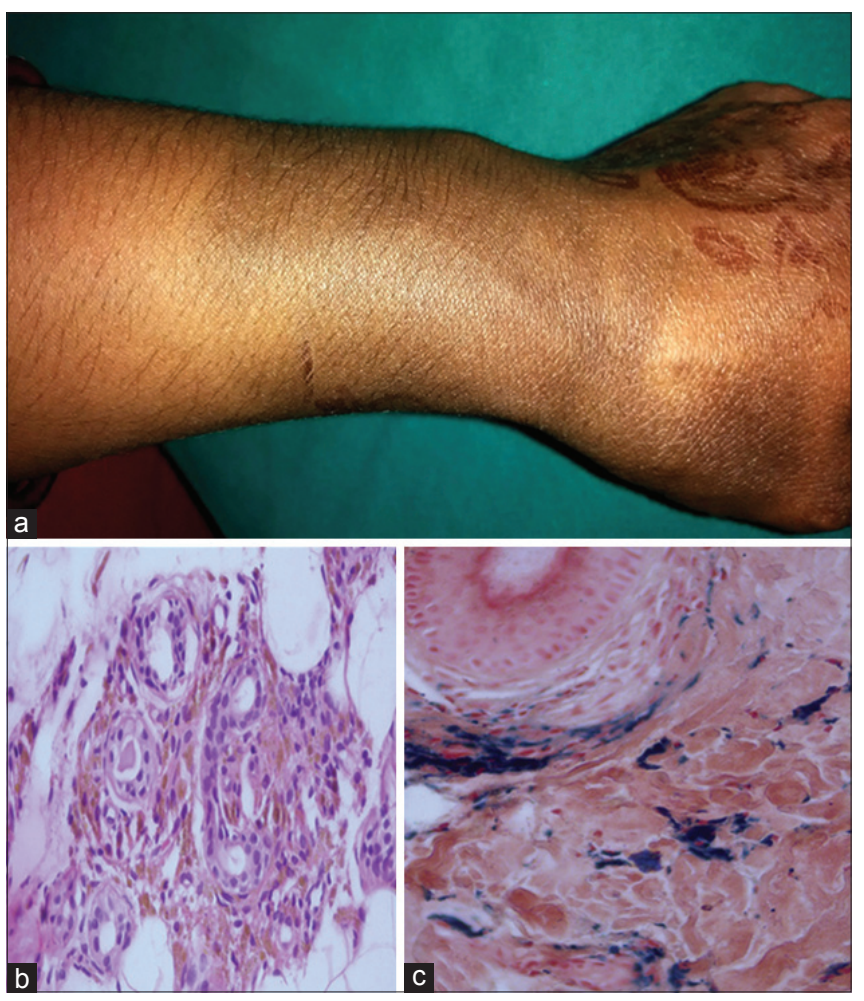

Fig 1:(a)- Greyish-brown macule over dorsal aspect of forerm and wrist. (b) - Perivascular clustered brown granules (H\&E 40X). (c) Prussian blue staining showing perivascular blue granules in the dermis (Prussian blue 40X).

\footnotetext{
How to cite this article: Gupta M. Cutaneous siderosis after extravasation of intravenous iron infusion. Our Dermatol Online. 2018;10(2):217-218. Submission: 29.04.2018; Acceptance: 18.06.2018 DOI:10.7241/ourd.20192.33
} 
tissues. Sometimes the localized deposition of pigment particles in dermal vessels and adnexal structures can be seen. The deposition of iron can be confirmed by Prussian blue staining, which stains the iron particles [5].

The treatment of drug-induced hyperpigmentation is usually cessation of the drug. Recently, laser therapy has been used in some cases, and promising results have been obtained [2-4]. Raulin et al used Q-Switch laser therapy in patients who developed hyperpigmentation after intramuscular iron therapy, obtaining significant color lightening in the lesions in all cases; however, they could not attain complete regression [3]. Lloyd et al also achieved significant clearing of the lesion with Q-switched alexandrite laser after four sittings [4].

\section{CONSENT}

The examination of the patient was conducted according to the Declaration of Helsinki principles.

\section{REFERENCES}

1. Ozlu E, Karadag AS, Bilgili SG, Baram I. Cutaneous siderosis after intramuscular iron injections: a case report. Cutan Ocul Toxicol. 2014;33:348-50.

2. Lloyd AA, Graves MS, Ross EV. Cutaneous siderosis secondary to intramuscular iron dextran treated with 755-nm Q-switch alexandrite laser: A case report. Lasers Surg Med. 2015;47:386-7.

3. Raulin C, Werner S, Greve B. Circumscripted pigmentations after iron injections-treatment with Q-switched laser systems. Lasers Surg Med. 2001;28:456-60.

4. Ghorbel HH, Lacour JP, Passerson T. Successful treatment with 532-nm Q-switched Nd: YAG laser of cutaneous siderosis following intravenous iron extravasation. J Eur Acad Dermatol Venereol. 2015;29:818-9.

5. Akimoto M, Hara H, Suzuki H. Metallosis of the skin mimicking malignant skin tumour. Br J Dermatol. 2003;149:653.

Copyright by Mrinal Gupta. This is an open-access article distributed under the terms of the Creative Commons Attribution License, which permits unrestricted use, distribution, and reproduction in any medium, provided the original author and source are credited.

Source of Support: Nil, Conflict of Interest: None declared. 